\title{
Transport Properties of the Solid Polymer Electrolyte System $\mathrm{P}(\mathrm{EO})_{n}$ LITFSI
}

Ludvig Edman, Marca M. Doeff, Anders Ferry, John Kerr, and Lutgard C. De Jonghe

\section{Materials Sciences Division}

November 1999

Submitted to

Journal of Physical

Chemistry $B$

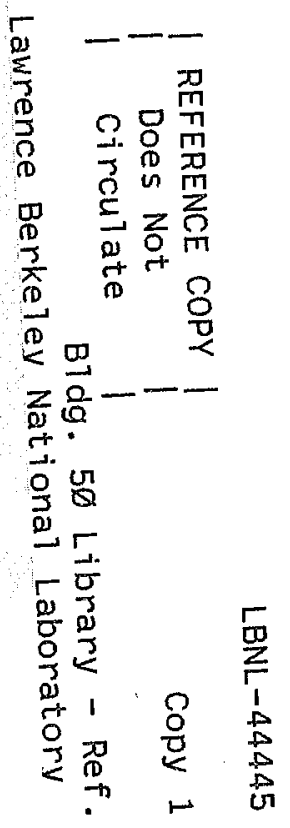




\section{DISCLAIMER}

This document was prepared as an account of work sponsored by the United States Government. While this document is believed to contain correct information, neither the United States Government nor any agency thereof, nor The Regents of the University of California, nor any of their employees, makes any warranty, express or implied, or assumes any legal responsibility for the accuracy, completeness, or usefulness of aly information, apparatus, product, or process disclosed, or represents that its use would not infringe privately owned rights. Reference herein to any specific commercial product, process, or service by its trade name, trademark, manufacturer, or otherwise, does not necessarily constitute or imply its endorsement, recommendation, of favoring by the United States Government or any agency thereof, or The Regents of the University of California. The views and opinions of authors expressed herein do not necessarily state or reflect those of the United States Government or any agency thereof, or The Regents of the University of California.

Ernest Orlando Lawrence Berkeley National Laboratory is an equal opportunity employer. 


\title{
Transport Properties of the Solid Polymer Electrolyte System P(EO) ${ }_{n}$ LITFSI
}

\author{
Ludvig Edman ${ }^{a}$, Marca M. Doeff ${ }^{\mathrm{a}}$, Anders Ferry ${ }^{\mathrm{b}}$, John Kerr ${ }^{\mathrm{c}}$, and Lutgard C. De \\ Jonghe \\ a,cLawrence Berkeley National Laboratory, Materials Science Division ${ }^{\mathrm{a}}$ and Environmental \\ Energy Technology Divisionc, University of California, Berkeley, California 94720, USA \\ bDepartment of Materials Engineering, Monash University, Clayton, 3168 VIC, Australia
}

\section{Acknowledgments}

This work was supported by the Assistant Secretary for Energy Efficiency and Renewable Energy, Office of Transportation Technologies, Office of Advanced Automotive Technologies of the U.S. Department of Energy under Contract No. DE-AC03-76SF00098. L.E. would like to thank the foundation Blanceflor Boncompagni-Ludovisi, née Bildt for financial support and A.F. acknowledges support by the Wenner-Gren foundation and from NFR. 
(7) rexycled paper 


\title{
Transport Properties of the Solid Polymer Electrolyte System P(EO) $)_{n}$ LITFSI
}

\author{
Ludvig Edman ${ }^{a, *}$, Marca M. Doeffa, Anders Ferry ${ }^{b}$, John Kerrc, and Lutgard C. De Jonghe ${ }^{a}$ \\ a,cLawrence Berkeley National Laboratory, Materials Science Division ${ }^{\mathrm{a}}$ and Environmental Energy \\ Technology Divisionc, University of California, Berkeley, California 94720, USA \\ bDepartment of Materials Engineering, Monash University, Clayton, 3168 VIC, Australia
}

\begin{abstract}
Values for the lithium ion transference number $\left(t_{+}^{0}\right)$ are reported for the solid polymer electrolyte system poly(ethylene oxide) (PEO) complexed with $\mathrm{Li}\left(\mathrm{CF}_{3} \mathrm{SO}_{2}\right)_{2} \mathrm{~N}$ (LiTFSI). $t_{+}^{0}$ ranges from $0.17 \pm$ 0.17 to $0.60 \pm 0.03$ in the salt concentration (c) region of 742 to $2982 \mathrm{~mol} / \mathrm{m}^{3}$ at $85^{\circ} \mathrm{C}$. The concentration dependence of $t_{+}^{0}$ and the molar ionic conductivity $(\Lambda)$ are shown to be in good agreement with a free volume approach over the salt-rich composition range investigated. The present $t_{+}^{0}$ results were obtained using a novel electrochemical technique based on concentrated solution theory. This experimentally straightforward method is herein demonstrated to give accurate results for a highly concentrated SPE system, without relying on any dubious simplifications regarding the state of the electrolyte.
\end{abstract}

\section{Introduction}

The concept of dissolving the salt of an alkaline metal in a polar macromolecule and thus creating an ion-conducting solid material, also called a solid polymer electrolyte (SPE), was initially proposed by Wright and coworkers more than two decades ago. ${ }^{1}$ Armand et al. subsequently proposed their use in electrochemical devices such as rechargeable lithium batteries. ${ }^{2}$ Much research effort has since then been directed towards understanding the complex chemistry and ionic transport properties of these

\footnotetext{
* Author to whom correspondence should be addressed: Address: Ludvig Edman; Department of Experimental Physics; Umeå University, S-901 87 Umeå; Sweden. E-mail: ludvig.edman@physics.umu.se. Fax: +4690786 6673.
} 
technologically important materials. ${ }^{3}$ A few years following Armand's proposal, it was established that phase diagrams of SPEs constitute so-called eutectic systems of one or more intermediate crystalline compounds with melting points well above room temperature. 4,5 Concurrently, it was recognized that significant long range ionic transport only takes place through amorphous regions; ${ }^{6}$ restricting use of SPEs based on, for instance, poly(ethylene oxide) (PEO) to moderately elevated temperatures. Several routes to suppress the formation of crystalline domains have since been explored, e.g., the inclusion of nano-sized fillers such as ceramic powders ${ }^{7,8,9}$ and fullerenes, ${ }^{10}$ as well as the incorporation of low molecular weight solvents. ${ }^{11}$ Another interesting avenue involves the development of novel salts with bulky anions such as $\mathrm{Li}\left(\mathrm{CF}_{3} \mathrm{SO}_{2}\right)_{2} \mathrm{~N}$ (lithium (bis)trifluoromethanesulfonate imide, LiTFSI), ${ }^{12}$ which are reported to act as plasticizers when complexed with PEO. ${ }^{13}$ Later reports have, however, shown that a crystalline eutectic system is the favored thermodynamic state for this system as well, at least for high molecular weight polymers, ${ }^{14}$ though the recrystallization kinetics are extremely slow. ${ }^{15}$

For the effective design of SPEs for advanced rechargeable batteries and other applications, the ionic transport properties must be thoroughly understood. In spite of extensive research efforts, however, it is often only the bulk ionic conductivity (i.e. the motion of both cations and anions) which is reported. This is somewhat surprising since it is only the cations that are electro-active towards the electrodes in a typical lithium polymer battery; hence the relative transfer of charge of this ionconstituent, the cationic transference number $\left(t_{+}^{0}\right)$, is a parameter of fundamental significance. ${ }^{16}$ Although some measurements of transference numbers in SPEs have been obtained, the results are inconsistent, ${ }^{17}$ most probably due to invalid simplifying assumptions regarding the ideality of electrolyte. ${ }^{18}$ The proliferation of papers in the literature reporting (invalid) data, with analyses relying on the "ideal" Nernst-Einstein relation, can be traced back to the inherent sticky and solid nature of SPEs, which largely precludes use of the classical Hittorf method (in which the electrolyte layer is sectioned and weighed after passage of current). ${ }^{19}$ In particular, the so-called 'ac impedance method ${ }^{20}$ is still frequently applied, ${ }^{7}$ despite glaring theoretical shortcomings apparent when dealing with concentrated solutions. ${ }^{18}$

To overcome these difficulties, a new electrochemical Hittorf method, general in nature but especially useful for solid materials such as SPEs, was developed by Newman and coworkers recently. ${ }^{21}$ It is based on concentrated solution theory and allows calculation of the cationic 
transference number from the results of three different electrochemical measurements, concentration cell, restricted diffusion and current interrupt experiments. ${ }^{3 b, 21,22}$

In this paper, we present results from these electrochemical measurements with the calculated lithium ion transference numbers and molar ionic conductivities as a function of salt concentration, for LiTFSI dissolved in PEO. All results were obtained at $85^{\circ} \mathrm{C}$ to ensure that samples were singlephase, and to facilitate a comparison with previously published data on related systems ${ }^{21,23,24,25}$ Since the calculation of the cationic transference number is dependent on three different experimental parameters, we also included a careful error analysis.

\section{Experimental}

High molecular weight PEO (Aldrich, $\mathrm{M}_{\mathrm{w}}=5 \cdot 10^{6} \mathrm{~g} / \mathrm{mol}$ ) was dissolved in acetone and recrystallized in order to remove the butylhydroxytoluene (BHT) stabilizer. LiTFSI, a gift from the 3M Company, was dried at $180^{\circ} \mathrm{C}$ for at least 12 hours under vacuum. The P(EO) ${ }_{n} \mathrm{LiTFSI}$ electrolytes were synthesized in a glove box under helium $\left(\mathrm{O}_{2}<1 \mathrm{ppm}\right)$ by dissolving pre-weighed amounts of polymer and salt in acetonitrile. The clear solutions were stirred and then cast into glass rings on Tefloncoated plates. Further drying took place for at least 24 hours under vacuum in order to remove the solvent. During this process, care was taken not to heat the electrolytes.

The bulk molar salt concentration $(c)$ as a function of $n$ (corresponding to O:Li, the ether oxygen to lithium ratio) was measured by placing weighed electrolytes in pycnometric flasks of known volume $\left(10 \mathrm{~cm}^{3}\right)$ filled with $\mathrm{n}$-heptane. The weight of the flask before and after displacement of the liquid allowed densities and, subsequently, $c$ values to be calculated for each electrolyte. $n$ values from 3 to 100 corresponded to salt concentrations covering the $3970-255 \mathrm{~mol} / \mathrm{m}^{3} \mathrm{range}$.

Concentration cells of the configuration $\mathrm{Li} / \mathrm{P}(\mathrm{EO})_{m} \mathrm{LiTFSI} / \mathrm{P}(\mathrm{EO})_{n} \mathrm{LiTFSI} / \mathrm{Li}$ were assembled on glass substrates under an inert helium atmosphere, with $m$ kept constant at 12 while $n$ was varied between 5 and 50. All interfaces were established through edgewise overlap of the lithium and/or SPE films, respectively, thereby providing for diffusion pathways of several centimeters in each phase. This was done to prevent a relaxation of the induced concentration gradients on the time scale of the experiment. ${ }^{21,22}$ A high input impedance electrometer (Keithley 642) was used for data acquisition in order to eliminate effects of cell polarization not stemming from the pre-set 
concentration gradient. A mathematical relation between the cell potential and the concentration gradient in the form of $\mathrm{d} U / \mathrm{d} \ln c$ was achieved using a $4^{\text {th }}$ order polynomial fit of the measurement data using Origin ${ }^{\text {TM }}$ software.

For the restricted diffusion and current interrupt measurements, symmetrical cells with lithium electrodes, the electrolyte, and a $76 \mu \mathrm{m}$ thick polypropylene spacer were assembled in the glove box. The whole "cell sandwich" was put into airtight Swagelok ${ }^{\mathrm{TM}}$ cells before being transferred to a convection oven (estimated temperature stability of $\pm 0.5^{\circ} \mathrm{C}$ ) for a 24 hour thickness equilibration at $85^{\circ} \mathrm{C}$. A computer controlled Arbin multichannel potentiostat/galvanostat was used for the galvanostatic polarizations required for both experimental quantities. To obtain values for the salt diffusion coefficient $\left(D_{s}\right)$, the method of restricted diffusion was used, which also provides values of high accuracy for concentrated solutions. ${ }^{26}$ Following an initial polarization, the relaxation of the potential $(\Delta \Phi)$ towards equilibrium for a SPE of known thickness $(L)$ was monitored. At long times, the following relationship, in which $C_{1}$ is a constant, holds true:

$\ln (\Delta \Phi)=-\pi^{2} D_{\varsigma^{t}} / L^{2}+C_{1}$

The aim of the current interrupt experiments is to establish concentration gradients at the electrode surfaces without allowing the concentration boundary layers to propagate to the middle of the cell. The upper limit for the polarization time $\left(t_{i}\right)$ in order to fulfill this requirement was set by the condition..$^{21}$

$t_{i}<<L^{2} / D_{s}$

With this requirement fulfilled, the established salt concentration gradient $(\Delta c)$ over the full cell is directly proportional to the anionic transference number $\left(t_{-}^{0}\right)$, in accordance with equation (3), where $I$ is the current density and $F$ represents Faraday's constant. For a thorough derivation of this key equation, the original work should be consulted. ${ }^{21}$

$\Delta c=4 t_{-}^{0}\left(I t_{i}\right)^{1 / 2} / F\left(\pi D_{S}\right)^{1 / 2}$ 
By using the relationship between the cationic and anionic transference number, ${ }^{27}$ as described in equation (4), it is mathematically relatively straightforward to rewrite the above equation to obtain $t_{+}^{0}$ as a function of three parameters accessible from previously described experiments. In order to make this final equation more compact, the parameter $m$ has been made to represent the initial slope of a plot of cell potential vs. $\left(I t_{i}^{1 / 2}\right)$.

$t_{+}^{0}\left(m, D_{s}, \mathrm{~d} U / \mathrm{d} \ln c\right)=1-t_{-}^{0}=1-\left(m c \mathrm{~F}\left(\pi D_{s}\right)^{1 / 2} /(4 \mathrm{~d} U / \mathrm{d} \ln c)\right)$

For the AC conductivity measurements, preparations were identical to those of the current interrupt experiments with the notable exception that blocking stainless steel electrodes were used instead of lithium electrodes. The impedance of an electrolyte was determined for a frequency range of $65 \mathrm{kHz}$ to $1 \mathrm{~Hz}$, with a Solartron ${ }^{\mathrm{TM}}$ SI 1254 four-channel frequency response analyzer coupled to a 1286 electrochemical interface, with the bulk resistance taken as the touchdown point of the semi-circle or spur on the $Z^{\prime}$-axis of a Nyquist plot.

The Gauss approximation formula was used to estimate the accuracy of our data (error bars included in figure 5). ${ }^{28}$ For $m$ and $D_{S}$ the standard deviation calculated at each discrete salt concentration was used for the error, while the error in $c$ was set to zero considering its comparatively small size. For the error in the quantity $\mathrm{d} U / \mathrm{d} \ln c$, we chose to calculate the maximum difference between the derivative of the fit presented in equation (5) and the slope of two adjacent potential readings as presented in figure (4). This approach probably overestimates the error, especially at low salt concentrations, but the trend showing an increasing $t_{+}^{0}$ value with increasing salt content is still significant.

\section{Results and Discussion}

The first quantity needed for the determination of $t_{+}^{0}$ is $m$, i.e., the initial slope in a plot of potential vs. $\left(I t_{i}^{1 / 2}\right)$, obtained from current interrupt experiments; this subsequently required a whole set of independent experiments to be performed for each salt concentration. A notable problem in

obtaining these data points originated in the occurrence of two superimposed effects - a concentration potential and a "double layer" potential - resulting from the galvanostatic polarization. 
One way to de-convolute the former is to make use of the comparatively long time scale on which it dissipates as compared to the latter (minutes vs. milliseconds), ${ }^{22}$ and to plot the potential vs. the dimensionless time $\left(T=t_{i}^{1 / 2} /\left(t^{1 / 2}+\left(t-t_{i}\right)^{1 / 2}\right) ; t_{i}=\right.$ polarization time $) \cdot{ }^{29} \mathrm{~A}$ linear extrapolation of the potential at long times $(T<1)$ back to the time of the current interrupt $(T=1)$ then allows the concentration potential at the time of the current interrupt $\left(\Delta \Phi_{0}\right)$ to be determined. This concept is visualized in figure 1 for $\mathrm{P}(\mathrm{EO})_{12} \mathrm{LiTFSI}$, which initially had been galvanostatically polarized at 150 $\mu \mathrm{A} / \mathrm{cm}^{2}$ for 34.29 seconds. This polarization time also fulfills the requirement set by equation (2), since the characteristic values of this study of $L=76 \cdot 10^{-6} \mathrm{~m}$ and $D_{S}<6 \cdot 10^{-12} \mathrm{~m}^{2} / \mathrm{s}$ leads to $t_{i}<<$ 1000 seconds. The SPE systems $\mathrm{PEO}-\mathrm{NaCF}_{3} \mathrm{SO}_{3}{ }^{21}$ and $\mathrm{PPO}-\mathrm{LiCF}_{3} \mathrm{SO}_{3}{ }^{23}$ (PPO $=$ poly(propylene oxide) showed a negative dependence on $m$ with $c$ in contrast to PEO-NaTFSI ${ }^{24}$, but for the PEOLiTFSI system, as seen in figure 2 , no monotonic relationship was observed.

In figure 3, a plot of the natural logarithm of potential vs. time for the relaxation of the galvanostatically polarized electrolyte $\mathrm{P}(\mathrm{EO}){ }_{12} \mathrm{LiTFSI}$ is presented. The slope of this plot at long times, i.e. when the cell is recovering its initial undisturbed condition, is directly proportional to the salt diffusion coefficient in accordance with equation (1). To get reliable data on this slope and hence $D_{S}$, it was necessary to polarize the cell substantially; for the measurement described in figure 3 , a current density of $250 \mu \mathrm{A} / \mathrm{cm}^{2}$ was used for 300 seconds. In comparison, the salt diffusion coefficients for PEO-LiTFSI are of the same magnitude as those of the PEO-NaTFSI ${ }^{24}$ and PEO$\mathrm{NaTf}^{21}$ systems but are significantly larger than those of the PPO-LiTf system. ${ }^{23}$

The dependence of potential on the logarithm of salt concentration, i.e. a concentration cell plot, is shown in figure 4. For each concentration at least four independent measurements were performed since the property $\mathrm{d} U / \mathrm{d} \ln c$, on which $t_{+}^{0}$ is dependent, is extremely sensitive to small experimental errors. The maximum deviation between the calculated mean value and a data point was $5 \mathrm{mV}$ corresponding to a relative error of $2.6 \%$. All data points were used for the $4^{\text {th }}$ order polynomial fit presented below.

$$
U(\ln c)=22.275632-14.143573 \cdot \ln c+3.3606198 \cdot(\ln c)^{2}-0.35640522 \cdot(\ln c)^{3}+0.014270731 \cdot(\ln c)^{4}(5)
$$


By differentiating equation (5), all variables included in equation (4) are available; and in figure 5 the transference number of the lithium ion as a function of bulk molar concentration in the salt rich region is presented. As can be seen, $t_{+}^{0}$ is positive over the entire concentration range with a small positive dependence on $c$. Our results readily reproduces and extends a recent study performed by Rey and coworkers using confocal Raman spectroscopy in which they report a $t_{+}^{0}$ value of $0.29 \pm$ 0.08 for $n=20$ at $80^{\circ} \mathrm{C} .{ }^{25}$ Another study on transference numbers of the PEO-LiTFSI system has also been reported using NMR spectroscopy, ${ }^{30}$ but since that analysis was relying on the NernstEinstein equation it is valid only for ideal, dilute solutions. ${ }^{18,31}$

High values for $t_{+}^{0}$ are somewhat remarkable, especially considering previously studied SPE systems in which $t_{+}^{0}$ exhibited a negative dependence on $c$, with very negative values for high salt concentrations. ${ }^{21,23,24}$ Although it has been shown that a battery can function despite very low or even negative values of $t_{+}^{0}, 32$ this is strongly coupled to detrimental effects such as salt depletion or precipitation. These negative events are related to the formation of a severe concentration gradient over the electrolyte during charge/discharge in agreement with the following relationship. 16,21

$\Delta c \approx I\left[1-t_{+}^{0}(c)\right] L / F D_{S}$

It is therefore desirable to develop and accurately identify SPEs with the highest possible cationic transference numbers. Unfortunately, other SPE systems with positive $t_{+}^{0}$ values ${ }^{23,33}$ have low ionic conductivities, indicating that anions and anionic complexes are relatively immobile, rather than that the mobility of the cations is improved. No such compromise is seen in the PEO-LiTFSI system. Thus, our observation of positive values for the PEO-LiTFSI system is indeed very promising. Another attractive characteristic of this electrolyte system is the relative insensitivity of $t_{+}^{0}$ to changes in $c$ (see figure 5) which prevents a "snowball effect" in the $\Delta c$ and $t_{+}^{0}$ values during cell operation in accordance with equation 6. The "snowball effect" refers to a situation in which transport properties become markedly less favorable as the salt concentration increases on one side of operating cells, causing premature shutdown. 
Figure 6 shows a plot of the molar ionic conductivity $(\Lambda)$ as a function of salt concentration, calculated from data obtained in this laboratory. There is a good qualitative agreement with previously published results although somewhat lower absolute values are observed, possibly due to the higher molecular weight of the polymer used in this study as compared to that used by Prud'homme and coworkers $\left(5 \cdot 10^{6}\right.$ vs. $\left.3.9 \cdot 10^{3}\right) \cdot 13,34,35$ For $c$ values ranging from 500 to $3000 \mathrm{~mol} / \mathrm{m}^{3}$, there is a decrease in $\Lambda$ with increasing salt concentration at $85^{\circ} \mathrm{C}$. This trend, regularly seen in SPEs at salt rich compositions; can be explained in the context of different modes of ionic motion. According to Bruce et al. the cationic motion can be "visualized as the making and breaking of coordinate bonds with motion between coordinating sites, while anion motion is regarded as hopping between an occupied site and a void which is large enough to contain the ion". ${ }^{36}$ It is also concluded from vibrational spectroscopy that there is negligible ionic association even at concentrated solutions for this specific system, ${ }^{37}$ in sharp contrast to other SPEs such as PEO$\mathrm{LiCF}_{3} \mathrm{SO}_{3}{ }^{38,39}$ In fact, Rey et al. could not detect any signs of ion pairs or larger aggregates at $80^{\circ} \mathrm{C}$ even in such a concentrated solution as $\mathrm{P}(\mathrm{EO}){ }_{8} \mathrm{LiTFSI} .{ }^{37}$

This suggests that the decrease in $\Lambda$ with $c$ for this specific system is largely attributable to a decrease in mobility of the anions due to a decrease in free volume with increasing density ( $\rho$ increases from 1192 to $1663 \mathrm{~kg} / \mathrm{m}^{3}$ for $n$ ratios going from 30 to 3), and hence that the cationic mobility and the carrier concentrations are static variables in $c$ in comparison. This conjecture is corroborated by the data presented in figure 5 , in which the increase in $t_{+}^{0}$ with $c$ consequently is attributed to the decrease in the mobility of the anions. It is also interesting to see that the relatively large positive dependence of $t_{+}^{0}$ with $c$ at low $c$ values $\left(750 \mathrm{~mol} / \mathrm{m}^{3}<c<1500 \mathrm{~mol} / \mathrm{m}^{3}\right)$ coincides with a stronger dependence of $\Lambda$ with $c$ in the same salt concentration range. It is alsoworth noting that Vincent and coworkers have reported a concentration independence for the diffusion coefficient of the lithium cation in the salt-rich regime in a SPE containing another bulky anion, $\mathrm{PF}_{6} \cdot{ }^{40}$ To further elucidate these issues, we will initiate complementary pulsed field gradient NMR diffusion studies (both anion and cation) of this particular system, as well as other representative SPEs, to be correlated with accurate $t_{+}^{0}$ determinations, as described herein. 


\section{Conclusions}

A recently developed electrochemical technique based on concentrated solution theory has been used to obtain the cationic transference number as a function of salt concentration at $85^{\circ} \mathrm{C}$ for the system PEO-LiTFSI. The high $t_{+}^{0}$ values (e.g. $t_{+}^{0}=0.60 \pm 0.03$ for O:Li $=5$ ) with a positive dependence on $c$ reported are in contrast with previous studies on other SPEs, but readily reproduces and extends a recent study using an independent confocal Raman method on the same system. Thus, we have shown that the very straightforward electrochemical method developed by Newman and coworkers yields accurate and reliable results, without relying on erroneous assumptions or special dedicated equipment. In addition, we report that the ionic conductivity is not compromised by the high $t_{+}^{0}$ values, in contrast to other SPE systems with this feature. We also suggest that the

concentration dependences of $t_{+}^{0}$ and $\Lambda$ in PEO-LiTFSI are attributable to a decrease in anion mobility with decreasing free volume.

\section{Acknowledgments}

This work was supported by the Assistant Secretary for Energy Efficiency and Renewable Energy, Office of Transportation Technologies, Office of Advanced Automotive Technologies of the U.S. Department of Energy under Contract No. DE-AC03-76SF00098. L.E. would like to thank the foundation Blanceflor Boncompagni-Ludovisi, née Bildt for financial support and A.F. acknowledges support by the Wenner-Gren foundation and from NFR. 


\section{Figure Captions}

\section{Figure 1}

Plot of the relaxation of potential $(\Delta \Phi)$ vs. the dimensionless time $(T)$ for P(EO) ${ }_{12} \mathrm{LiTFSI}$ at $85^{\circ} \mathrm{C}$ after a galvanostatic polarization $\left(I=150 \mu \mathrm{A} / \mathrm{cm}^{2} ; t_{i}=34.29\right.$ seconds $)$. The solid line represents a linear extrapolation back to time of the current interrupt $(T=1)$ allowing the initial concentration potential, $\Delta \Phi_{0}$, to be determined.

\section{Figure 2}

Current interrupt data taken for representative $\mathrm{P}(\mathrm{EO})_{n} \mathrm{LiTFSI}$ electrolytes at $85^{\circ} \mathrm{C}$. The initial slope, i.e. when $I t_{i}^{1 / 2} \rightarrow 0$, is used as the $m$ value in equation (4).

\section{Figure 3}

Semi-logarithmic plot of potential $(\ln (\Delta \Phi))$ vs. time $(t)$ for a galvanostatically polarized $\mathrm{P}(\mathrm{EO}){ }_{12} \mathrm{LiTFSI}$ electrolyte at $85^{\circ} \mathrm{C}$. The solid line represents a linear fit for data at long times after the current interrupt, for determination of the salt diffusion coefficient $\left(D_{s}\right)$ (equation 1). ${ }^{\text {Errorl Bookmark }}$ not defined. 26

\section{Figure 4}

Concentration cell data for $\mathrm{Li} / \mathrm{P}(\mathrm{EO})_{m} \mathrm{LiTFSI} / \mathrm{P}(\mathrm{EO})_{n} \mathrm{LiTFSI} / \mathrm{Li}$ cells at $85^{\circ} \mathrm{C} . c$ (and $n$ ) represents the salt concentration of the latter electrolyte whereas $m$ is kept constant at a value of 12 , corresponding to a salt concentration of $1537 \mathrm{~mol} / \mathrm{m}^{3}$. The dashed line represents the polynomial fit described in equation (5).

\section{Figure 5}

Lithium transference number $\left(t_{+}^{\circ}\right)$ as a function of salt concentration $(c)$ at $85^{\circ} \mathrm{C}$. The dashed line is a fit to the $t_{+}^{0}$ data, and the error bars are calculated as described in the text.

\section{Figure 6}

Molar ionic conductivity $(\Lambda)$ for the $\mathrm{P}(\mathrm{EO})_{\mathrm{n}} \mathrm{LiTFSI}$ system as a function of salt concentration $(c)$ at $85^{\circ} \mathrm{C}$. The dashed line is a polynomial fit to experimental data. 


\section{References}

${ }^{1}$ Fenton, D.E.; Parker, J.M.; Wright, P.V. Polymer 1973, 14, 589.

2 Armand, M.B.; Chabagno, J.M.; Duclot, M.J. In Fast Ion Transport in Solids; Vashista, P., Mundy, J.N., Shenoy, G.K., Eds.; Elsevier North Holland: New York, 1979; p. 131.

${ }^{3}$ For recent reviews, see: (a) Ferry, A. In Recent Research Developments in Macromolecules Research, Pandalai, S.G., Ed.; Research Signpost: Trivandrum, India, 1999; Vol. 4, p. 79; (b) Ferry, A.; Doeff, M.M. In Current Trends in Polymer Science; Richard, R. (Ed.); Research Trends: Trivandrum, India, 1998; Vol. 3, p. 117.

${ }^{4}$ Robitaille, C.; Prud'homme, J. 65 $5^{\text {th }}$ Canadian Chemical Congress, Toronto, Canada, 1982; Abstract No. MA-10.

${ }^{5}$ Robitaille, C.D.; Fauteaux, D. J. Electrocbem. Soc. 1986, 133, 315.

${ }^{6}$ Berthier, C.; Gorecki, W.; Minier, M.; Armand, M.B.; Chabagno, J.M.; Rigaud, P. Solid State Ionics $1983,11,91$.

${ }^{7}$ Croce, F.; Appetecchi, G.B.; Persi, L.; Sćrosati, B. Nature 1998, 394, 456.

${ }^{8}$ Wieczorek, W.; Zalewska, A.; Raducha, D.; Florjanczyk, Z.; Stevens, J.R. J. Pbys. Chem. B 1998, $102,352$.

${ }^{9}$ Best, A.S.; Ferry, A.; MacFarlane, D.R.; Forsyth, M. Solid State Ionics, in press.

10 Edman, L.; Ferry, A.; Jacobsson, P. Macromolecules 1999, 32, 4130.

11 Bishop, A.G.; MacFarlane, D.R.; McNaughton, D.; Forsyth, M. J. Phys. Chem., 1996, 100, 2237.

${ }^{12}$ Armand, M.; Gorecki, W.; Andréani, R. Second International Symposium on Polymer Electrolytes 1990, 91.

13 Vallée, A.; Besner, S.; Prud'homme, J. Electrocbim. Acta 1992, 37, 1579.

${ }^{14}$ Labrèche, C.; Lévesque, I.; Prud'homme, J. Macromolecules 1996, 29, 7795.

15 Edman, L.; Ferry, A.; Doeff, M.M. J. Mater. Res., submitted for publication.

${ }^{16}$ Doyle, M.; Fuller, T.F.; Newman, J. Electrocbim. Acta 1994, 39, 2073.

17 Fritz, H.P.; Kuhn, A. J. Power Sources 1993, 41, 253.

${ }^{18}$ Doyle, M.; Newman, J. J. Electrochem. Soc. 1995, 142, 3465.

19 Bruce, P.G.; Haregrave, M.T.; Vincent, C.A. Solid State Ionics 1992, 53-56, 1087.

${ }^{20}$ Bruce, P.G.; Vincent, C.A. J. Electroanal. Chem. 1987, 225, 1.

${ }^{21}$ Ma, Y.; Doyle, M.; Fuller, T.F.; Doeff, M.M.; De Jonghe, L.C.; Newman, J. J. Electrochem. Soc. $1995,142,1859$. 
${ }^{22}$ Ferry, A.; Doeff, M.M.; De Jonghe, L.C. Electrochim. Acta 1998, 43, 1387.

${ }^{23}$ Doeff, M.M., Georén, P.; Qiao, J.; Kerr, J.; De Jonghe, L.C. J. Electrochem. Soc. 1999, 146, 2024.

${ }^{24}$ Ferry, A.; Doeff, M.M.; De Jonghe, L.C. J. Electrochem. Soc. 1998, 145, 1586.

${ }^{25}$ Rey, I.; Bruneel, J.-L.; Grondin, J.; Servant, L.; Lassègues, J.-C. J. Electrochem. Soc. 1998, 145, 3034.

${ }^{26}$ Newman, J.; Chapman, T.W. AICbE J. 1973, 19, 343, and references therein.

27 See, for instance: Spiro, M. In Tecbniques of Chemistry, Weissberger, A.; Rossiter, B.W., Eds.;

Wiley: New York, 1970; Vol. 1, Part 1A.

${ }^{28}$ See, for instance: Vännman, K. In Matematisk Statistik, Centek Förlag: Luleå, Sweden, 1986; p. 143.

${ }^{29}$ Newman, J. Personal communication.

${ }^{30}$ Gorecki, W.; Jeannin, M.; Belorizky, E.; Roux, C.; Armand, M. J. Pbys.: Condens. Matter 1995, 7, 6823.

31 Bockris, J. O’M.; Reddy, A.K.N. In Módern Electrochemistry 1 - Ionics, Plenum Press: New York, 1998, p. 459.

32 Cameron, G.G.; Harvie, J.L.; Ingram, M.D. Solid State Ionics 1989, 34, 65.

${ }^{33}$ Doeff, M.M.; Edman, L.; Sloop, S.E.; Kerr, J.; De Jonghe, L.C. J. Power Sources, submitted for publication.

34 Benrabah, D.; Baril, D.; Sanchez, J.-Y.; Armand, M.; Gard, G.G. J. Chem. Soc., Faraday Trans. 1993, $89,355$.

${ }^{35}$ Lascaud, S.; Perrier, M.; Vallée, A.; Besner, S.; Prud'homme, J.; Armand, M. Macromolecules 1994, 27, 7469.

${ }^{36}$ Bruce, P.G.; Gray, F.M. In Solid State Electrochemistry, Bruce, P.G., Ed.; University Press: Cambridge, 1995; p. 140.

${ }^{37}$ Rey, I.; Lassègues, J.-C.; Grondin, J.; Servant, L. Electrochim. Acta 1998, 43, 1505.

${ }^{38}$ Frech, R.; Chintapalli, S.; Bruce, P.G. Vincent, C.A. Chem. Commun. 1997, 157.

${ }^{39}$ Frech, R.; Chintapalli, S.; Bruce, P.G. Vincent, C.A. Macromolecules 1999, 32, 808.

40 Arumugam, S.; Shi, J.; Tunstall, D.P.; Vincent, C.A. J. Pbys-Condens. Mat. 1993, 5, 153. 


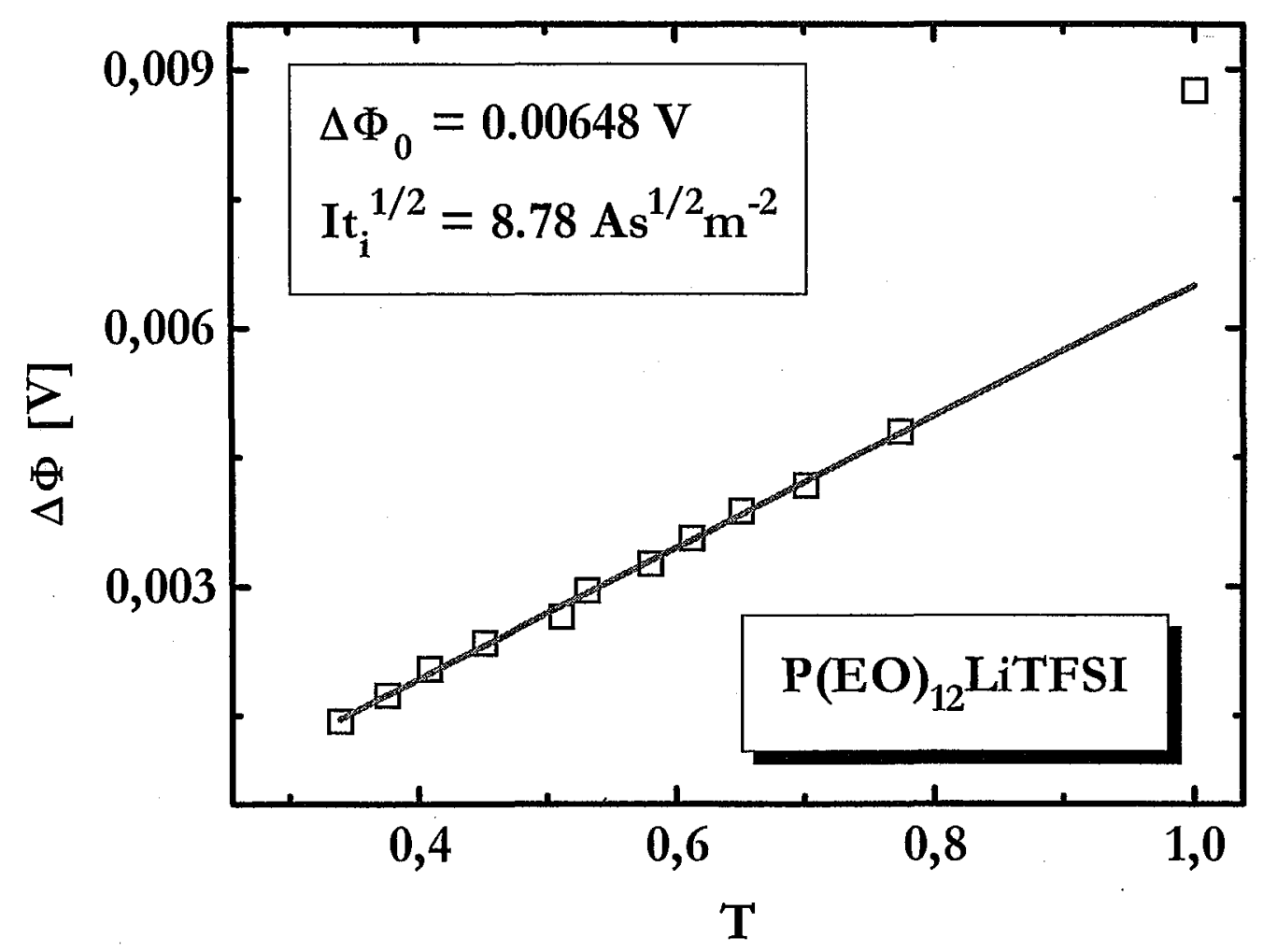

Figure 1, Edman et al, "Transport Properties of ...", Journal of Physical Chemistry 


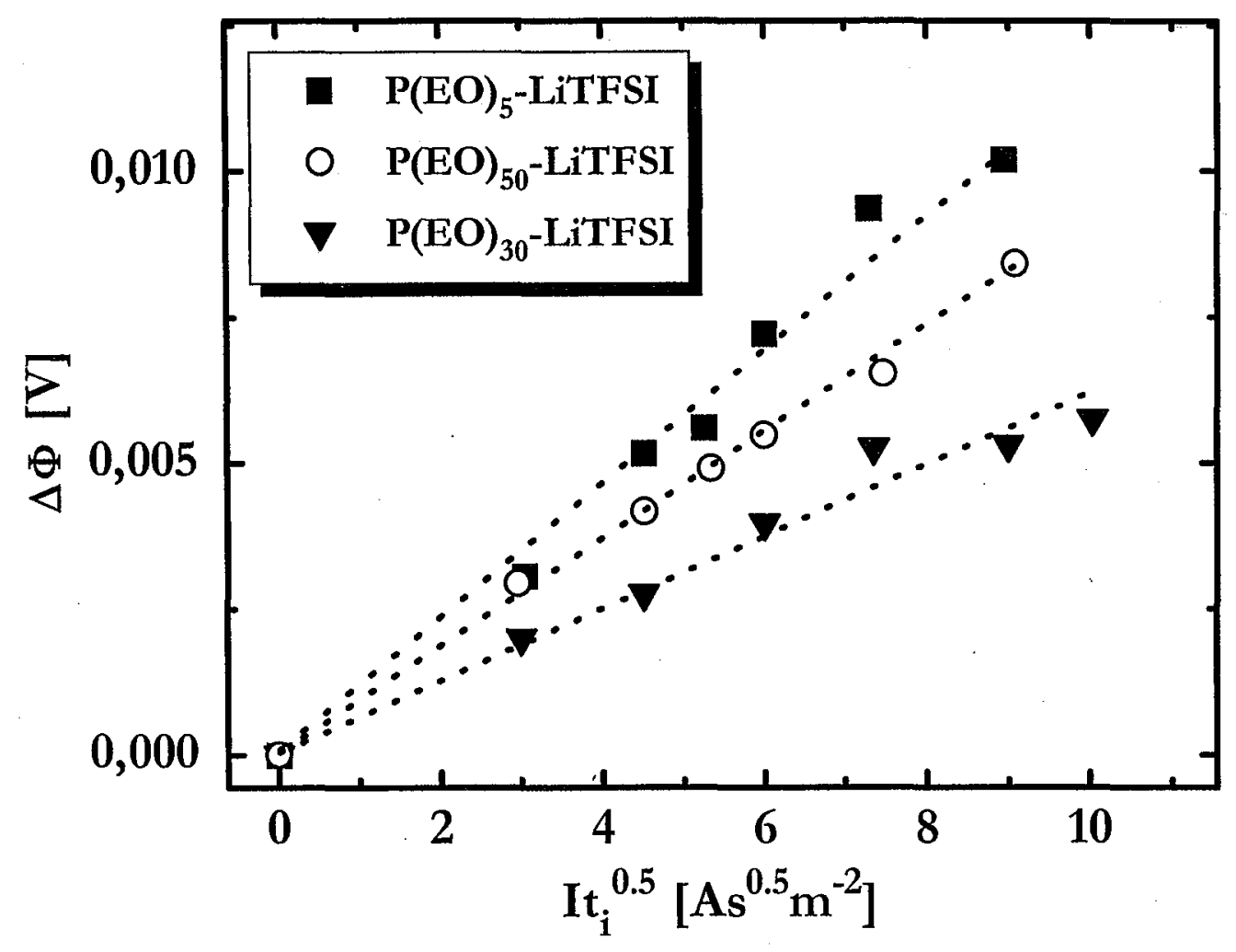

Figure 2, Edman et al, "Transport Properties of ...", Journal of Physical Chemistry 


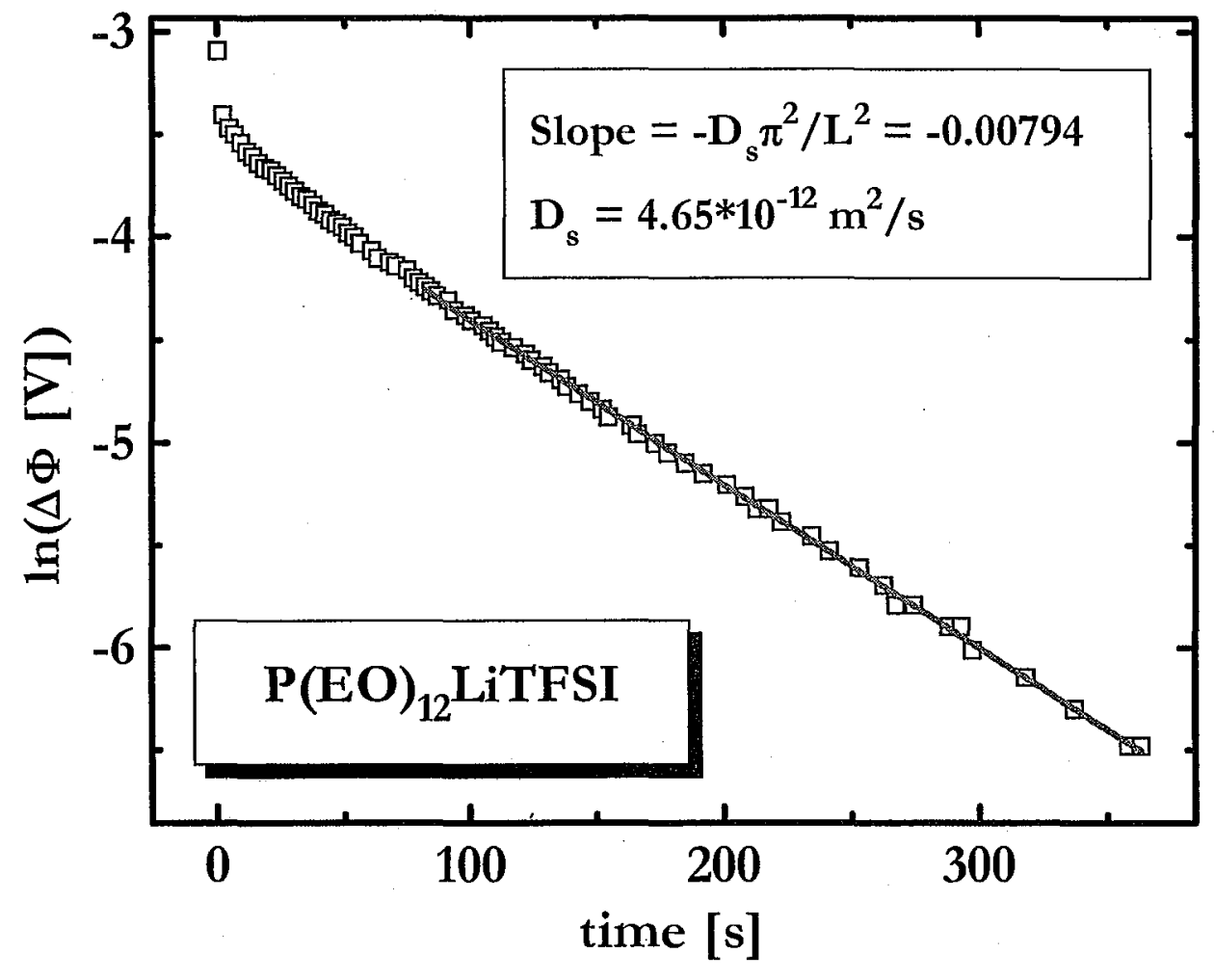

Figure 3, Edman et al, "Transport Properties of ...", Journal of Physical Chemistry 


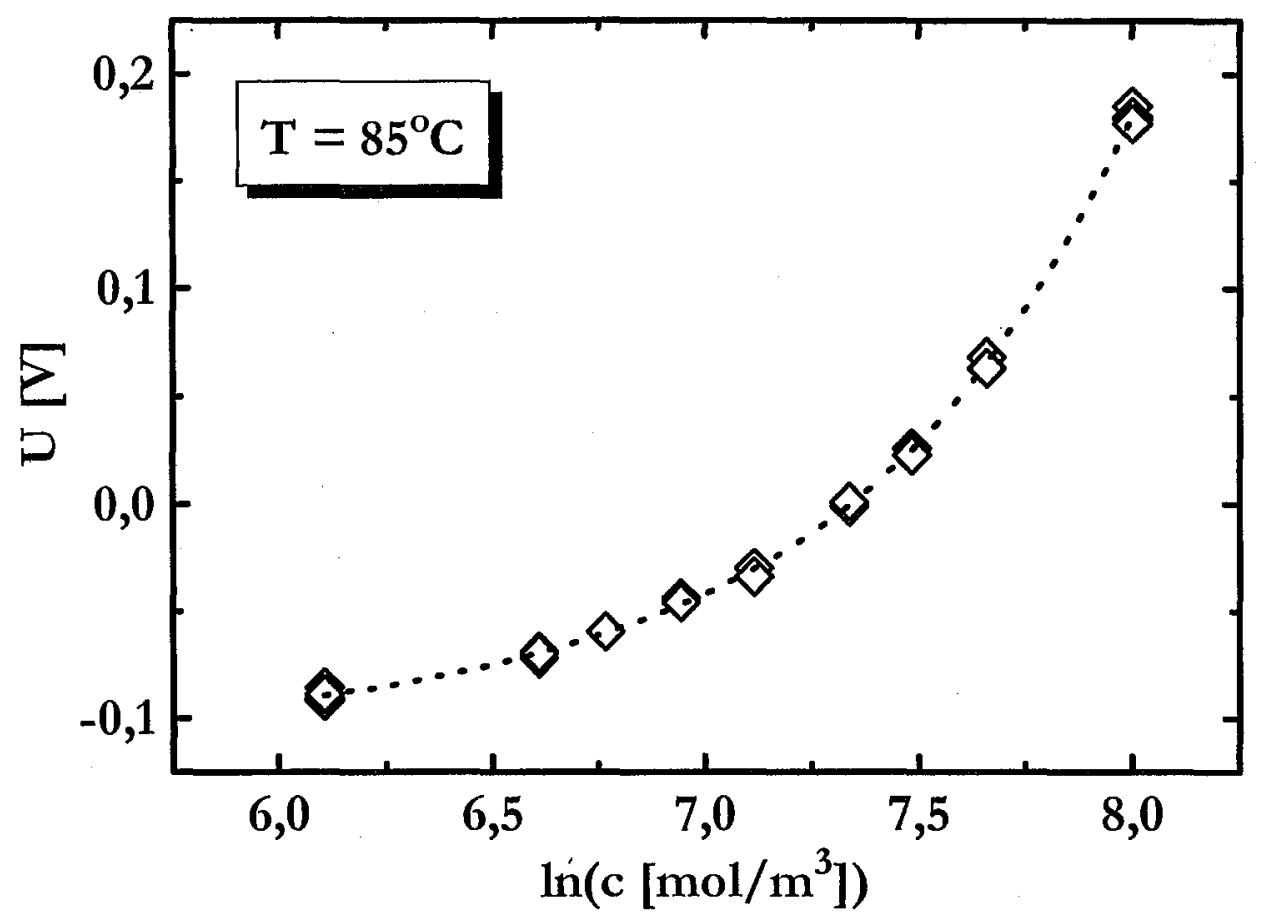

Figure 4, Edman et al, "Transport Properties of ...", Journal of Physical Chemistry 


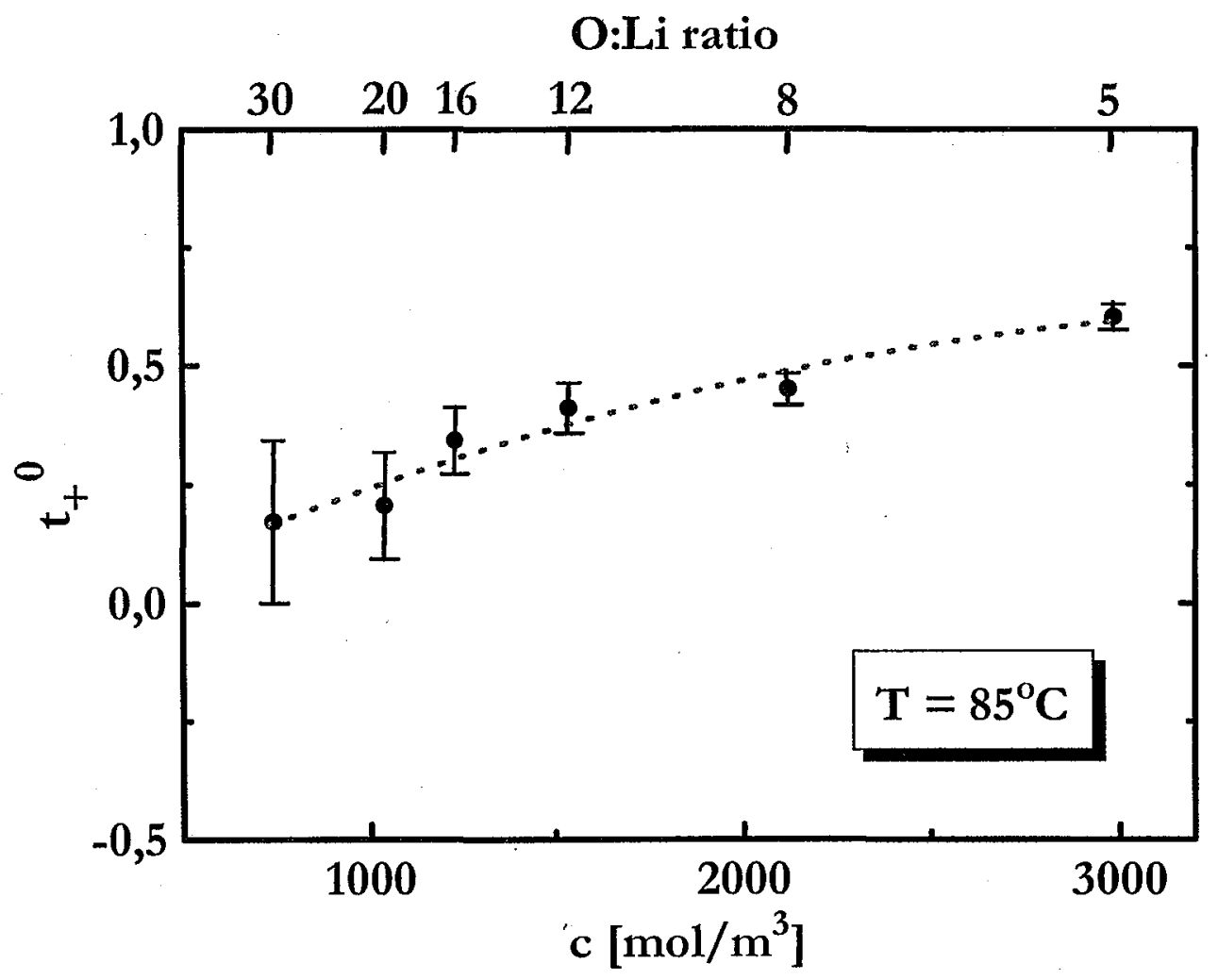

Figure 5, Edman et al, "Transport Properties of ...", Journal of Physical Chemistry 


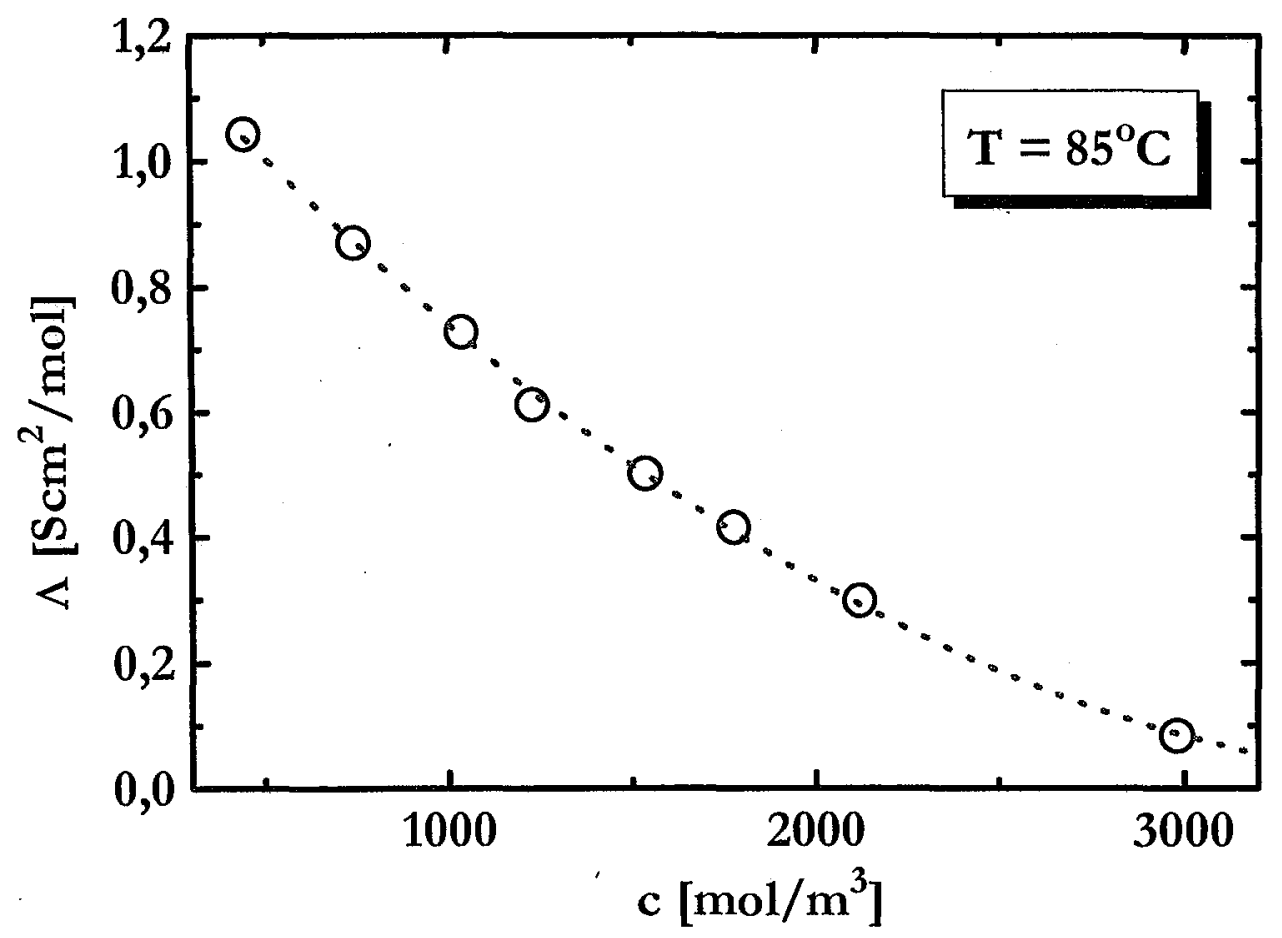

Figure 6, Edman et al, "Transport Properties of ...", Journal of Physical Chemistry 